\title{
The influences of meteorological factors on the health and functional state of human
}

\author{
Reza Sharafi ${ }^{1^{*}}$, Volodymyr B. Bogdanov², Dmytro S. Gorlov ${ }^{1}$, Yuriy P. Gorgo ${ }^{3}$ \\ ${ }^{1}$ Taras Shevchenko National University of Kyiv, Kiev, Ukraine; ${ }^{*}$ Corresponding Author: ramin2121@gmail.com \\ ${ }^{2}$ University of Liege, Liege, Belgium \\ ${ }^{3}$ Kyiv Polytechnic Institute, Kiev, Ukraine
}

Received 27 October 2013; revised 28 November 2013; accepted 7 December 2013

Copyright (C) 2013 Reza Sharafi et al. This is an open access article distributed under the Creative Commons Attribution License, which permits unrestricted use, distribution, and reproduction in any medium, provided the original work is properly cited.

\begin{abstract}
The influence of fluctuations of atmospheric pressure on the functional state of the humans was studied during spring, autumn and winter seasons. Sensory-motor reaction time and selfreported wellbeing, activity and mood were used for evaluation of functional state. The inter-individual variations of those parameters were compared to meteorological parameters using rank order correlation and general linear model. It was found that atmospheric pressure fluctuations have a stronger negative effect with periods of $120-1200 \mathrm{~s}$ and $20-120 \mathrm{~s}$ on psychological self-assessment and with periods of 10 $20 \mathrm{~s}$ and $5-10 \mathrm{~s}$ on sensory-motor reaction time than the fluctuations with other periods.
\end{abstract}

Keywords: Weather; Functional State; Reaction Time Task; Wellbeing; Activity; Mood

\section{INTRODUCTION}

Weather conditions include many different factors: the atmospheric pressure and its oscillations, temperature, humidity and wind velocity. Each of them has an impact on the mood and the functional state [FS] of humans. Functional state of man is an integrative characteristic of an individual's efficiency of his role and activities involved in its implementation of systems according to the criteria of reliability and internal rates of activity [1].

Pristrom \& Mrochek 2002 stated [2] that in the developed countries, approximately one third of the population has an increasing sensitivity to the change of weather. Negative symptoms such as headache, weakness, pain in joints and palpitation may appear at the same time or just before a sudden change in temperature and atmospheric pressure. Severity of the symptoms depends on the adaptation to such changes, age and diseases. The physiological reactions sometimes can occur without being perceived consciously. Cognitive functions are most sensitive to meteorological changes. Short term memory, attention and reaction time are sensitive to rapid changes in weather factors $[3,4]$. The effect of the environmental factors increases by their simultaneous action, even if the amplitude of each factor is separately too small for triggering the reaction $[3,5]$.

\subsection{Temperature Effects}

Marchenko et al. 1998 [6] have shown that temperature conditions influence the processes of thermoregulation and metabolism, change muscular and nervous activity and biochemical and bioelectric processes. Low air temperature affects the strongly cognitive activity [7]. Low temperature reduces cognitive activity, attention and concentration via distraction and increase in arousal $[4,8]$. The impact of temperature on the organism to a great extent depends on the humidity of air. At heightened humidity, the impact of high and low temperature is increased [6].

\subsection{Atmospheric Pressure Effects}

Changes of atmospheric pressure mechanically influence circulation by constriction of superficial capillaries, located in the skin and respiratory pathways. Low atmospheric pressure slows down heart rate and increases the respiratory volumes [9]. The increase of atmospheric pressure decreases the number of leucocytes, mainly neutrophils [9]. The changes of the number of neutrophils and leukocytes are the indexes of changing the general state of the autonomic nervous system. Lowering of atmospheric pressure activates the sympathetic nervous system, causes the increase of reaction time, suppresses mood and reduces ability to work. Oppositely, the increase of atmospheric pressure induces activation 
of parasympathetic nervous system [9].

\subsection{Wind Velocity Effects}

The effect of wind is ambiguous. Influences of wind on human health are due to effects of environmental concomitants such as ambient temperature, humidity, atmospheric pressure and positive ion concentrations [10]. In cold weather, wind increases heat irradiation, and also potentates the influence of humidity. Influence of wind velocity on organism will mediate directly on skin, and by heating or cooling, this effect depends on other factors like relative humidity and temperature. A climate with large fluctuations in temperature and high wind velocity is unfavorable for people, predisposition to the increase of arterial pressure. Wind speed, exceeding 10 $\mathrm{m} / \mathrm{s}$, negatively affects the wellbeing of patients [6].

Rapid changes of air pressure, air temperature, hot, sweltering and sultry days, very frosty days, days with strong or foehn wind, days with thunderstorms, fog and haze were selected as unfavorable weather factors. They give an occasion for strong psychical stress [11]. The effects of winds blowing from the mountains (foehn wind) on human mental activity, characterized by parameters such as reaction time and duration of active attention, and indirect indications such as the behavior resulting in traffic accidents were considered in a number of studies [12,13]. Lee and Garraway [14] found a significant effect of wind strength on the risk of sport injuries. The heightened anxiety levels in people with mental disorders increase in suicide incidence and the more frequent occurrences of cardiac arrhythmias on days with strong wind are likely, at least partly, to be due to some biological response to wind-generated rapid atmospheric pressure fluctuations (APF) [15-17]. The meanings of the effects of wind are attributed to concurrent rapid APF.

\subsection{Atmospheric Pressure Fluctuations Effects}

There are emerging number of studies of effects air pressure fluctuations and their impact on human health and wellbeing. The most powerful source of APF in stormy weather is the chaotic turbulent airflows induced by strong wind [17-24]. The influence of APF may createsubstantial changes in the attention, working memory, cognitive performance and mental flexibility. Therefore, APF are supposed to be able to raise the risk of neurological disorders [9]. The important feature of APF is that man does not feel their alterations, and therefore, cannot consciously estimate their action on the mental state and wellbeing [17]. The adverse effects of AFP during stormy weather storm on road accidents were reported [24]. This can be explained by the observation that modeled $\mathrm{APF}$ in the infrasound frequency range $(0.003 \mathrm{~Hz}<\mathrm{f}<1$
$\mathrm{Hz} \sim 1 \mathrm{sec}-20 \mathrm{~min}$ ) can affect cognitive functions, especially attention [2,17-22,24,25]. APF penetrate buildings [22,26] and, therefore, could be responsible for weather sensitivity symptoms not only outdoors, but also indoors. It is believed that natural APF could affect the human body through the reactions of tympanic membrane [24]. Some authors suggested that the special area, pars flaccida in the tympanic membrane containing elastin fibers, is actually a middle ear sensor for pressure fluctuations [27,28]. In favor of this view, the mechanical reactions of pars flaccida in response to very little changes in the middle ear pressure, as well as to slight pressure oscillations in far infrasound range, were demonstrated by the experimental studies on animals [27, 29].

Some authors believe that there is a pathway, through which changes in the pressure are transmitted from the middle ear to the inner ear and influence the activity of the otolithic receptors. This activity consequently affects the firing rates of the vestibular afferent fibers and of the neurons in the vestibular nucleus [30]. It is also shown that vestibular activity is dependent on the rates of ambient pressure changes in the middle ear. It is larger under higher rates of pressure changes [31]. In our experiment we wanted to evaluate effects of APF using simple sensory-motor reaction time task and wellbeing selfassessment.

\subsection{Reaction Time Task and Psychological Self-Assessment}

Reaction time (RT) depends on the state of central nervous system [32-36]. RT increases in conditions of reduced attention [33]. It was already shown that RT is a sensitive measure of meteorological responses. RT considerably deteriorates at high temperature and lowering of atmospheric pressure [9,25,37].

Cold ambient temperature decreases body core temperature and reduce RT [38,39]. Seasonal variation of mood is characterized by onset of depression in winter/autumn [40]. Seasonal depression and other seasonal affective disorder occurring during autumn and winter months are most common in young women, although it can affect men or women of any age, these seasons' negatively affect wellbeing, activity and mood. Studies based on violent homicides, suicides, and aggressive behaviors have repeatedly demonstrated seasonal characteristics, typically with peaks in the spring [41-43].

We expected that increased APF can contribute to seasonal depressive symptoms. The aim of our study was to show effects of APF on functional state and wellbeing self-report. Between subject variability was correlated to the current meteorological parameters of interest. Conventional meteo-data (air temperature, wind velocity and atmospheric pressure) were used as possible confounds. 
Therefore, we compared effects of temperature, atmospheric pressure, wind velocity and fluctuations of atmospheric pressure on self-estimated wellbeing, activity and mood and on reaction time task. In this paper different seasons were used for the study of effects of various weather conditions on wellbeing, activity and mood and reaction time task in unlike ethnic groups. Because of the literature data, the various effects of meteorological parameters and APF on the functional state of men and women were expected in different seasons. We expected that APF and wind velocity have more negative effects on both RT and psychological self-assessment because of distraction and increase of arousal level.

\section{MATERIAL AND METHODS}

\subsection{Participants}

The study was performed in tow geographical regions: Kyiv (Ukraine) and Shiraz (Iran) and during three distinct seasons: spring (14 March to 13 April), autumn (28 September to 28 October) in Kyiv and winter (9 February to 4 April) in Shiraz. In the spring 48 men and 27 women, in autumn 15 men and 20 women and in winter 25 men were studied. On the whole 135 volunteers in three groups were studied. Ages of participants were 15 30 years old. The study design was approved by local ethical committee.

\subsection{Experimental Design}

At the beginning of the experiment, all the subjects sign the informed consent and fill the questionnaires about "wellbeing, activity and mood" WAM [44]. Then we measured the simple reaction time (RT) to visual stimuli by the computer program designed by us on the personal computer (monitor 14", 640/480 Pixels). The stimulus signal was a white square with an area of 1000 pixels on the black background. Linear sizes of the side of the square were $11 \mathrm{~mm}$, angular sizes- $1^{\circ} 20^{\prime}$. General radiance was measured by "Digital Luxmeter MS6610". The luminosity of the workplace at a distance of $0.5 \mathrm{~m}$ from the monitor was established at the level $6-15 \mathrm{Lux}$. 100 signals were exposed with intervals of $1500-3000$ ms randomly changed.

Volunteers who stayed in front of the monitor (distance from the monitor to the eyes was about $50 \mathrm{~cm}$ ), were given the following instructions: "On presence of every stimulus you should press any key on the keyboard as fast as possible. Not be distracted, do not speak during the test, do not press the key prematurely i.e. before the appearance of the stimulus." Responses less than $100 \mathrm{~ms}$ were considered as errors, and responses that took longer than $500 \mathrm{~ms}$ were excluded, too. The experimental task was as long as 5 minutes. First 10 trails and total average of reaction times were used for estimation of individual average reaction rime (RT) values and standard deviations (SD) for further analysis. Standard deviation measures the degree of variability or diversity among variables. Standard deviation is a measure of variability around a mean. Standard deviation is important because it aids in making statistical studies and researches more reliable, accountable and valid.

The average increase of time of RT and SD was interpreted by us as a decrease of functional state. First 10 values where specifically valuable to evaluate ability to gain rapidly simple task related skills. The total RT was the measures of ability of have high and sustained performance.

\subsection{Meteorological Data Collection}

Monitoring of APF was carried out continuously, round-the-clock, during all the time of research by the electronic micro barometer "Atmospher-P1" ("Dobruyshlyah", Kyiv, Ukriane), which was disposed outdoors. Atmospheric pressure oscillations were recorded from 650 to $1080 \mathrm{~Pa}$ (from 489 to $812 \mathrm{mmHg}$ ), with the sensitivity of $1 \mathrm{~Pa}$ and acquisition rate of $1 \mathrm{sec}$. Recorded information was written down in the memory of the device and was passed for storage and processing on a personal computer.

The data of APF were analyzed with a specialized program on the basis of the package of MatLab (The MathWorks Inc.). By the methods of digital spectral filtration (rapid transformation of Fourier) to select pressure fluctuation in 5 ranges of periods: I-from $120 \mathrm{~s}$ to $1200 \mathrm{~s}$; II-from $20 \mathrm{~s}$ to $120 \mathrm{~s}$; III-from $10 \mathrm{~s}$ to $20 \mathrm{~s}$; IV—from $5 \mathrm{~s}$ to $10 \mathrm{~s} ; \mathrm{V}$-from $3 \mathrm{~s}$ to $5 \mathrm{~s}$. Also, for each of 5 noted ranges, analysis was done for every hour of frequency constituent (harmonic) with the maximal value of amplitude and the hourly amplitude of fluctuations in this range was calculated. From APF parameters we have taken $\mathrm{AD}$ (the detected amplitude of signal in the range).

Standard meteorological data (temperature of air, wind velocity, atmospheric pressure,) in the period of experiment were obtained from the meteorological center of airport of Juliany of Kyiv, Ukraine and the national meteorological center of Shiraz, Iran. Following statistical processing were made with the program of Statistica 8.0 (StatSoft, USA). The relationships between psychological and physiological measures and current meteorological parameters were estimated by Spearman rank order correlation and General Linear Models.

\section{RESULTS}

Table 1 shows the means and Standard Errors of groups' characteristics in 3 season of experiment. 
Table 1. Means with Standard Errors of groups characteristics.

\begin{tabular}{|c|c|c|c|c|c|}
\hline $\begin{array}{l}\text { Variable } \\
\text { mean }(\mathrm{SE})\end{array}$ & $\begin{array}{l}\text { Men spring group } \\
\quad(\mathrm{n}=48)\end{array}$ & $\begin{array}{l}\text { Women spring group } \\
\qquad(\mathrm{n}=27)\end{array}$ & $\begin{array}{l}\text { Men autumn group } \\
\qquad(\mathrm{n}=15)\end{array}$ & $\begin{array}{l}\text { Women autumn group } \\
\qquad(\mathrm{n}=20)\end{array}$ & $\begin{array}{l}\text { Men winter group } \\
\quad(\mathrm{n}=25)\end{array}$ \\
\hline Age & $20.3(0.32)$ & $20.0(0.73)$ & $20.5(0.46)$ & $20.3(0.42)$ & $21.6(0.87)$ \\
\hline Wellbeing & $0.667(0.022)$ & $0.661(0.027)$ & $0.684(0.027)$ & $0.628(0.044)$ & $0.707(0.025)$ \\
\hline Activity & $0.602(0.022)$ & $0.588(0.024)$ & $0.553(0.028)$ & $0.521(0.038)$ & $0.563(0.023)$ \\
\hline Mood & $0.687(0.022)$ & $0.727(0.025)$ & $0.697(0.032)$ & $0.707(0.036)$ & $0.712(0.028)$ \\
\hline M1-10 & $235.5(5.75)$ & $244.8(6.56)$ & 229.7 (5.48) & $261.1(9.67)^{\varnothing \mu \mu}$ & $224.3(8.91)^{\# \#}$ \\
\hline SD1-100 & $48.90(3.42)$ & $46.63(4.12)$ & $55.53(4.48)$ & $55.53(4.48)$ & $49.24(5.00)$ \\
\hline M1-100 & $233.4(4.12)$ & $242.0(6.22)$ & 246.5 (7.17) & $256.0(7.17)^{\emptyset \mu \mu}$ & $229.0(8.59)^{\# \#}$ \\
\hline SD1-100 & $44.06(1.92)$ & $45.11(2.18)$ & $44.60(2.27)$ & $44.60(2.27)$ & 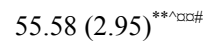 \\
\hline
\end{tabular}

RT-Reaction time; M1-10: mean 1 - 10 RT trails; M1-100: mean 1 - 100 RT trails; SD1-10: Standard Deviation 1 - 10 RT trails; SD1-100: Standard Deviation 1 - 100 RT trails; *Significantly differences between Spring Men and Winter Men; Nignificantly differences between Autumn Men and Winter Men; ${ }^{\square}$ Significantly differences between Spring Women and Winter Men: ${ }^{\#}$ Significantly differences between Autumn Women and Winter Men; ${ }^{\varnothing}$ Significantly differences between Autumn Women and Autumn Men; ${ }^{\mu}$ Significantly differences between Autumn Women and Spring Men; ${ }^{*} \mathrm{p}<05,{ }^{* *} \mathrm{p}<01$.

\subsection{Characteristic of Atmospheric Parameters and AFP at the Time of Experiment}

The mean air temperature during the study of spring $\left(+5.2^{\circ} \mathrm{C}\right)$ was the lowest in compare with autumn $\left(+12^{\circ} \mathrm{C}\right)$ and winter $\left(+14.6^{\circ} \mathrm{C}\right)$ experiment and significantly differed. Mean atmospheric pressure during the study of winter in Shiraz was the lowest $(1017 \mathrm{hPa})$, but in autumn time in Kyiv was the highest $(1024 \mathrm{hPa})$ and significantly differed. The mean wind velocity at the time of study of spring was higher $(4.8 \mathrm{~m} / \mathrm{s})$ than autumn and winter experiment and significantly differed (Figure 1).

During the study of spring in Kyiv mean AD was lower and significantly differed from autumn experiment. Mean AD of APF for all of periods in time of study of autumn was higher than spring experiment in Kyiv and significantly differed. Mean $\mathrm{AD}$ during the study of winter in Shiraz except AD1 was lower than autumn time in Kyiv (Figure 2).

\subsection{Characteristics of WAM and RT, Intergroup and Sex Differences}

Anova test showed the significantly effect of sex differences on RT but season significantly not affected RT, also we did not find any significantly effect of sex and season on WAM.

Wellbeing, Activity and Mood in the springtime in Kyiv had better condition than the autumn time but in the winter in Shiraz had the best condition (Figure 3).

RT during the study of winter in Shiraz was the lowest and in the autumn time of experiment in Kyiv was the highest. Results shows that men in the spring and autumn time of study had lower RT than women and significantly differed from each other in the all ranges (Fig-

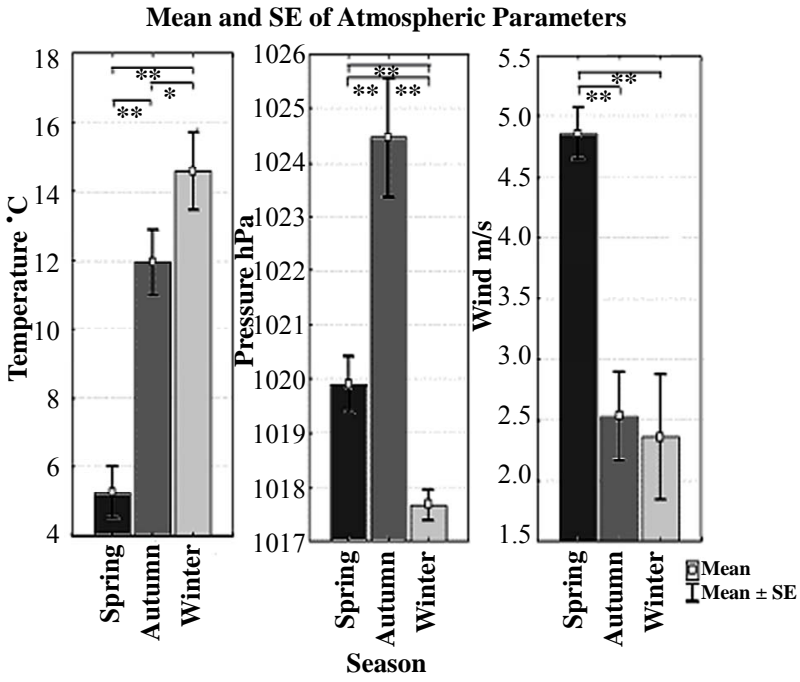

Figure 1. Characteristic of atmospheric parameters in 3 season conditions.

ure 4).

\subsection{Relationships of AFP (AD) with Atmospheric Parameters at the Time of Experiment}

In the springtime of experiment in Kyiv air temperature and atmospheric pressure negatively correlated with $\mathrm{AD}$ but wind velocity positively correlated. In the autumn time air temperature negatively correlated but atmospheric pressure and wind velocity positively correlated with $\mathrm{AD}$. In the wintertime in Shiraz air temperature and wind positively correlated with $\mathrm{AD}$. Our results show the most positive correlation relationships are between wind velocity with $\mathrm{AD}$ in all season of experiment, that may be indicates the most powerful source of APF is 


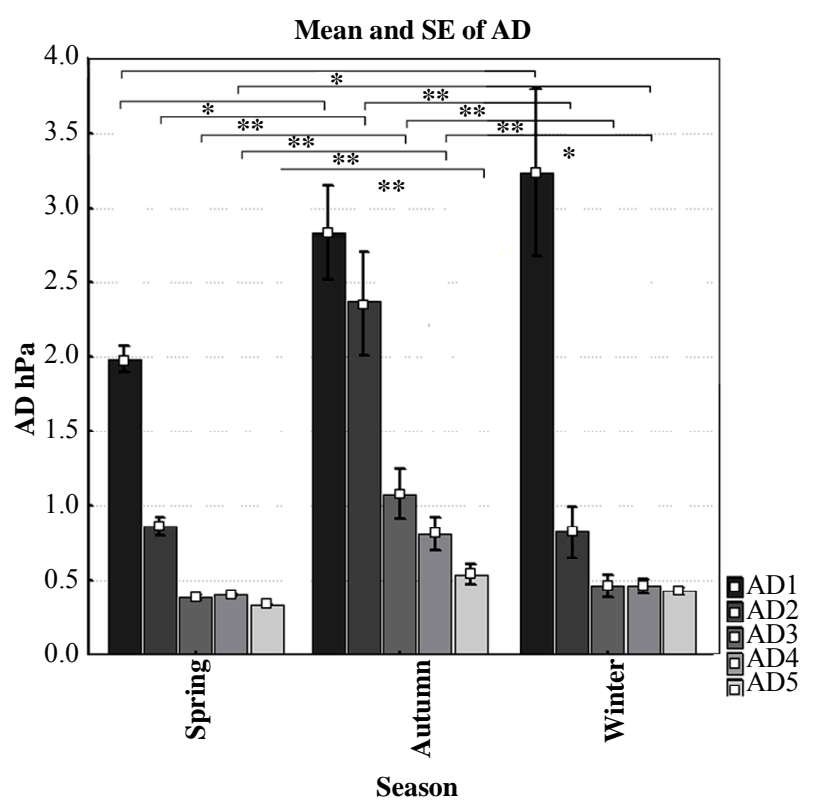

Figure 2. Characteristic of AFP (AD) in 3 season's conditions. $\mathrm{AD}$-the amplitude of signal found out in the range (all of harmonic), Pa; AD1: AD in I period (120-1200s), Pa; AD2: AD in II period (20 - $120 \mathrm{~s}), \mathrm{AD} 3$ : AD in III period $(10-20 \mathrm{~s}), \mathrm{AD} 4$ : $\mathrm{AD}$ in IV period (5 - $10 \mathrm{~s}), \mathrm{AD} 5$ : AD in V period $(3-5 \mathrm{~s}) ;{ }^{*} \mathrm{p}<$ $05,{ }^{* *} \mathrm{p}<01$.

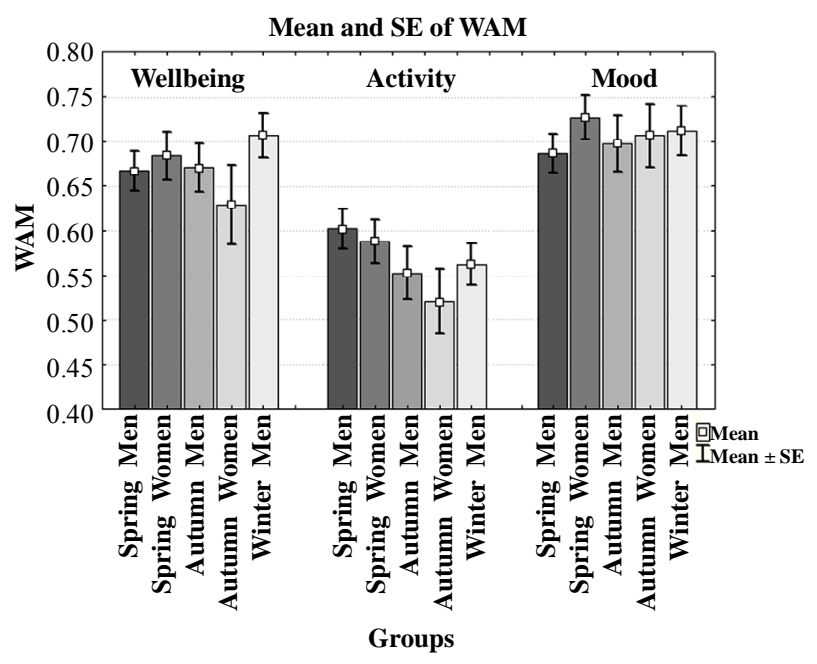

Figure 3. Characteristics of wellbeing, activity and mood (WAM) in groups.

wind velocity (Table 2).

\subsection{Relationships of Psychological Self-Assessment and Atmospheric Parameters}

In the springtime of experiment in Kyiv in men mood positively correlated with atmospheric pressure but activity and mood negatively correlated with wind velocity, women of this group only had single positive correlation

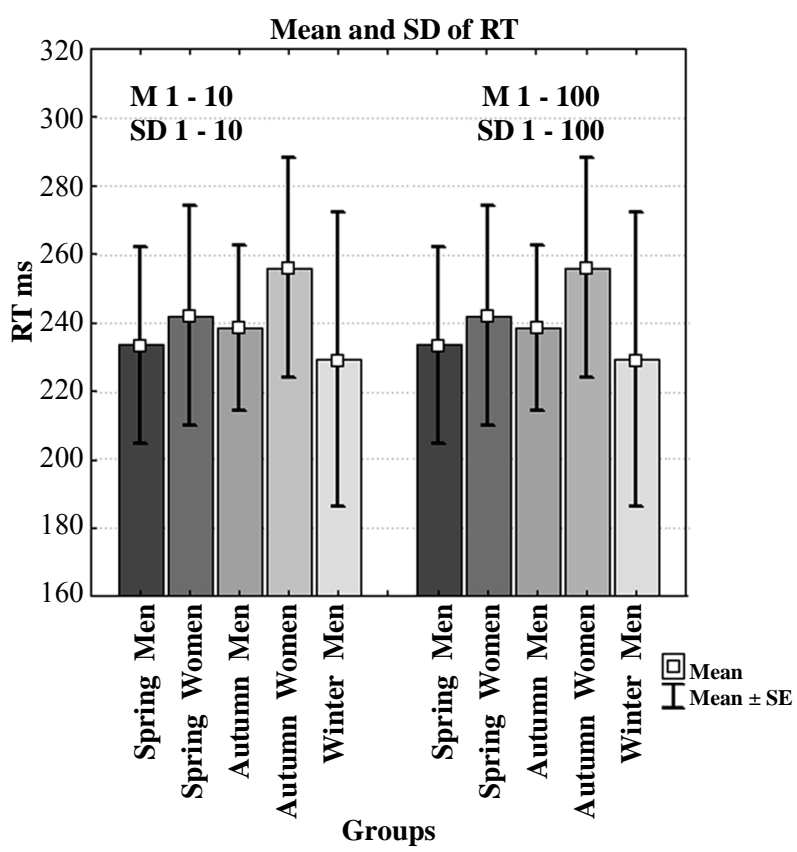

Figure 4. Characteristics of visual simple reaction time (RT) in groups.

Table 2. Correlation relationships of AFP (AD) with atmospheric parameters in spring, autumn and winter.

\begin{tabular}{|c|c|c|c|c|c|}
\hline & AD1 & AD2 & AD3 & AD4 & AD5 \\
\hline \multicolumn{6}{|c|}{ Spring } \\
\hline Temperature & & & $-0.33^{* *}$ & $-0.42^{* *}$ & $-0.42^{* *}$ \\
\hline Pressure & & $-0.54^{* *}$ & $-0.54^{* *}$ & $-0.60^{* *}$ & $-0.49^{* *}$ \\
\hline Wind & & $+0.69^{* *}$ & $+0.70^{* *}$ & $+0.71^{* *}$ & $+0.45^{* *}$ \\
\hline \multicolumn{6}{|c|}{ Autumn } \\
\hline Temperature & & $-0.44^{*}$ & $-0.37^{*}$ & & \\
\hline Pressure & & $+0.42^{*}$ & $+0.52^{* *}$ & $+0.47^{* *}$ & $+0.46^{*}$ \\
\hline Wind & $+0.62^{* *}$ & $+0.64^{* *}$ & $+0.66^{* *}$ & $+0.66^{* *}$ & $+0.65^{* *}$ \\
\hline \multicolumn{6}{|c|}{ Winter } \\
\hline Temperature & & $+0.86^{* *}$ & $+0.87^{* *}$ & $+0.95^{* *}$ & \\
\hline
\end{tabular}

Wind

$+0.69^{*} \quad+0.70^{*}$

$+0.61^{*}$

$\mathrm{AD}$ the amplitude of signal found out in the range (all of harmonic), Pa; $\mathrm{AD} 1$ : $\mathrm{AD}$ in I period $(120-1200 \mathrm{~s}), \mathrm{Pa}$; $\mathrm{AD} 2 \mathrm{AD}$ in II period $(20-120 \mathrm{~s})$, AD3: AD in III period (10 - 20 s), AD4: AD in IV period (5 - $10 \mathrm{~s})$, AD5: $\mathrm{AD}$ in $\mathrm{V}$ period $(3-5 \mathrm{~s}) ;{ }^{*} \mathrm{p}<05,{ }^{* *} \mathrm{p}<01$.

with atmospheric pressure. In the autumn time men had single negative correlation with atmospheric pressure but women had positive correlations with wellbeing, activity and mood. In wintertime of experiment in Shiraz activity and mood of men negatively correlated with air temperature. It's shown that wind velocity had more positive 
effect on women psychological self-assessment in the autumn time of our experiment but in men wind had negative effect in all season of our experiment (Table 3).

\subsection{Relationships of RT and Atmospheric Parameters}

In the springtime in men M1-10 and M1-100 RT positively correlated with atmospheric pressure and M1-10 RT positively correlated with wind velocity but in women SD1-10 negatively and M1-100 positively correlated with wind velocity. In the autumn time of experiment in men SD1-100 negatively correlated with air temperature and atmospheric pressure, but in women M1-10 and M1-100 positively correlated with air temperature.

Table 3. Correlation relationships and General Linear Models (GLM) between WAM-RT with atmospheric parameters in men and women.

\begin{tabular}{|c|c|c|c|}
\hline & Temperature & Pressure & Wind \\
\hline Wellbeing & & & $\mathrm{R}=+0.46^{*} \mathrm{WA}$ \\
\hline Activity & $\mathrm{R}=-0.38^{\wedge} \mathrm{MW}$ & $\begin{array}{l}\mathrm{R}=+0.35^{\wedge} \mathrm{WS} \\
\mathrm{R}=-0.63^{*} \mathrm{MA}\end{array}$ & $\begin{array}{c}-0.05^{*} \mathrm{MS} \\
+0.06^{\wedge} \mathrm{WA} \\
\mathrm{R}=+0.38^{\wedge} \mathrm{WA}\end{array}$ \\
\hline Mood & $\mathrm{R}=-0.38^{\wedge} \mathrm{MW}$ & $\begin{aligned} \mathrm{R} & =+0.28^{\wedge} \mathrm{MS}, \\
& +0.08^{\wedge} \mathrm{WA}\end{aligned}$ & $\mathrm{R}=-0.29^{*} \mathrm{MS}$ \\
\hline M $1-10$ & $\begin{array}{l}\mathrm{R}=+0.40^{\wedge} \mathrm{WA}, \\
\mathrm{R}=+0.43^{*} \mathrm{MW}\end{array}$ & $\mathrm{R}=+0.25^{\wedge} \mathrm{MS}$ & $+0.05^{*} \mathrm{MS}$ \\
\hline SD $1-10$ & & & $-0.07^{\wedge} \mathrm{WS}$ \\
\hline M $1-100$ & $\mathrm{R}=+0.56^{* *} \mathrm{MW}$ & $\mathrm{R}=+0.29^{*} \mathrm{MS}$ & $+0.09^{\wedge} \mathrm{WS}$ \\
\hline SD $1-100$ & $-0.02^{*} \mathrm{MA}$ & $+0.04^{*} \mathrm{MA}$ & \\
\hline
\end{tabular}

MS-men spring $(\mathrm{n}=48)$, WS-women spring $(\mathrm{n}=27)$ MA-men autumn $(\mathrm{n}=$ 15), WA-women autumn $(\mathrm{n}=20)$, MW-Men Winter $(\mathrm{n}=25)$; M1-10: mean 1-10 RT trails; M 1-100: mean 1-100 RT trails; SD1-10: Standard Deviation 1-10 RT trails; SD1-100: Standard Deviation 1-100 RT trails; ${ }^{\wedge}<0.1,{ }^{*} \mathrm{p}<$ $0.05,{ }^{* *} \mathrm{p}<0.01$.
In the wintertime in Shiraz M1-10 and M1-100 positively correlated with air temperature (Table 3).

\subsection{Relationships of Psychological Self-Assessment and Atmospheric Pressure Fluctuations}

In the springtime of experiment in Kyiv, wellbeing activity and mood of men and women negatively correlated with APF. There were for men in this time negative correlations between wellbeing with $\mathrm{AD} 2$, activity with AD1-AD2 and mood with AD1-AD4. For women there were negative significant correlations between wellbeing with AD2, AD4 and activity with AD4-AD5. In the autumn time only for men there were negatively correlations for data of wellbeing with AD1, AD3 and activity with $\mathrm{AD} 2$ and $\mathrm{AD} 4$. In wintertime of experiment data of activity negatively correlated with AD1, AD4 and mood also negatively correlated with AD1 and AD5. All of significant relationships of psychological self-assessment with AFP were negative (Table 4).

\subsection{Relationships of RT and Atmospheric Pressure Fluctuations}

In the springtime of experiment for men there were shown tow positive significant correlations between data of SD1-10 RT with AD4, SD1-100 with AD2 and single negative correlation between data of SD1-10 with AD5. In the women there were shown negatively correlations between SD1-10 with AD3-AD4 and M1-10 with AD4 and positively correlations were shown between M1-10 with AD3, M1-100 with AD4 and SD1-100 with AD1, $\mathrm{AD} 3$ and $\mathrm{AD} 4$. In the autumn time for men, there were shown only positive significant correlations between data of SD1-10 with AD1-AD5 and SD1-100 with AD1, AD2, AD3 but in the women of this group SD1-10 negatively

Table 4. Correlation relationships and general linear models (GLM) between WAM-RT with AFP (AD) in men and women.

\begin{tabular}{|c|c|c|c|c|c|}
\hline & AD1 & AD2 & AD3 & AD4 & AD5 \\
\hline Wellbeing & $\mathrm{R}=-0.52^{\wedge} \mathrm{MA}$ & $\begin{array}{l}\mathrm{R}=-0.26^{\wedge} \mathrm{MS} \\
\mathrm{R}=-0.35^{\wedge} \mathrm{WS}\end{array}$ & $-0.06^{\wedge} \mathrm{MA}$ & $\mathrm{R}=-0.37^{\wedge} \mathrm{WS}$ & \\
\hline Activity & $\begin{array}{c}\mathrm{R}=-0.32^{*} \mathrm{MS} \\
\mathrm{R}=-0.72^{* *} \mathrm{MW},-0.05^{\wedge} \mathrm{MS}\end{array}$ & $\begin{array}{l}\mathrm{R}=-0.29^{*} \mathrm{MS} \\
\quad-0.05^{*} \mathrm{MA}\end{array}$ & & $\begin{array}{c}\mathrm{R}=-0.41^{*} \mathrm{WS} \\
\mathrm{R}=-0.52^{\wedge} \mathrm{MW},-0.07^{\wedge} \mathrm{MA}\end{array}$ & $\mathrm{R}=-0.35^{\wedge} \mathrm{WS}$ \\
\hline Mood & $\begin{array}{l}\mathrm{R}=-0.28^{\wedge} \mathrm{MS} \\
\mathrm{R}=-0.60^{*} \mathrm{MW}\end{array}$ & $\mathrm{R}=-0.41^{* *} \mathrm{MS}$ & $\mathrm{R}=-0.47^{* *} \mathrm{MS}$ & $\mathrm{R}=-0.30^{\wedge}$ & $\mathrm{R}=-0.58^{*} \mathrm{MW}$ \\
\hline M 1-10 & & & $+0.09^{\wedge} \mathrm{WS}$ & $-0.05^{\wedge} \mathrm{WS}$ & \\
\hline SD1-10 & $\mathrm{R}=+0.72^{* *} \mathrm{MA}$ & $\begin{array}{l}\mathrm{R}=+0.55^{*} \mathrm{MA} \\
\mathrm{R}=-0.55^{*} \mathrm{WA} \\
\mathrm{R}=-0.51^{\wedge} \mathrm{MW}\end{array}$ & $\begin{array}{c}\mathrm{R}=+0.62^{*} \mathrm{MA}, \\
\mathrm{R}=-0.51^{\wedge} \mathrm{WA}, \\
\mathrm{R}=-0.54^{\wedge} \mathrm{MW},-0.09^{\wedge} \mathrm{WS}\end{array}$ & $\begin{array}{c}\mathrm{R}=+0.55^{*} \mathrm{MA}, \\
\mathrm{R}=+0.52^{*} \mathrm{WA}, \\
+0.09^{\wedge} \mathrm{MS},-0.07^{\wedge} \mathrm{WS}\end{array}$ & $\begin{aligned} \mathrm{R} & =+0.50^{\wedge} \mathrm{MA} \\
\mathrm{R} & =-0.56^{*} \mathrm{WA} \\
& -0.05^{\wedge} \mathrm{MS}\end{aligned}$ \\
\hline M 1-100 & & & & $+0.08^{\wedge} \mathrm{WS}$ & \\
\hline SD1-100 & $\begin{array}{c}\mathrm{R}=-0.47^{\wedge} \mathrm{WA}, \\
\mathrm{R}=+0.33^{\wedge} \mathrm{WS},+0.05^{*} \mathrm{MA}\end{array}$ & $\begin{aligned} \mathrm{R} & =+0.26^{\wedge} \mathrm{MS} \\
& +0.03^{*} \mathrm{MA}\end{aligned}$ & $\begin{array}{c}\mathrm{R}=+0.45^{*} \mathrm{WS} \\
+0.02^{*} \mathrm{MA},-0.09^{\wedge} \mathrm{WA}\end{array}$ & $+0.04^{*} \mathrm{WS}$ & \\
\hline
\end{tabular}

MS: men spring $(n=48)$, WS: women spring $(n=27)$ MA: men autumn $(n=15)$, WA: women autumn $(n=20)$, MW: men winter $(n=25)$. 
correlated with AD2, AD3 and AD5 and positively correlated with AD4 and SD1-100 negatively correlated with AD1 and AD3 (Table 4).

In the springtime of experiment for men there were shown tow positive significant correlations between data of SD1-10 RT with AD4, SD 1-100 with AD2 and single negative correlation between data of SD1-10 with AD5. In the women there were shown negatively correlations between SD1-10 with AD3-AD4 and M1-10 with AD4 and positively correlations were shown between M1-10 with AD3, M1-100 with AD4 and SD1-100 with AD1, $\mathrm{AD} 3$ and AD4. In the autumn time for men, were shown only positive significant correlations between data of SD1-10 with AD1-AD5 and SD1-100 with AD1, AD2, $\mathrm{AD} 3$ but in the women of this group SD1-10 negatively correlated with $\mathrm{AD} 2, \mathrm{AD} 3$ and $\mathrm{AD} 5$ and positively correlated with AD4 and SD1-100 negatively correlated with $\mathrm{AD} 1$ and $\mathrm{AD} 3$. In the wintertime of experiment only SD1-10 negatively correlated with AD2 and AD3 (Table 4).

\section{DISCUSSION}

\subsection{Effect of Atmospheric Parameters on WAM}

In the springtime of experiment, atmospheric pressure increased mood of males and females, but wind velocity caused negative changes in activity and decreased mood of males, and in females we didn't see any effect. In the autumn time, atmospheric pressure decreased activity of males, but at this time in females wind velocity increased wellbeing and activity. It's shown that wind velocity has more positive effect on females' psychological self-assessment in autumn time of our experiment, but in males, wind had a negative effect on the spring. In the wintertime of experiment (average temperature $+14.5^{\circ} \mathrm{C}$ ), the increase of temperature was related to decline of activity and mood in males (Table 3).

Significant correlations between atmospheric parameters and WAM show the more negative effect of wind velocity especially on activity and mood of males in spring period but show the positive effect of wind velocity on wellbeing and activity of females in the autumn period of the year. Brereton et al. (2008) [45] indicated that wind velocity has a significant negative influence on wellbeing but the negative effects of increases of wind in cold season was minimum and in hot season was maximum. Denissen et al. (2008) [46] indicated that windy day had more negative effects on mood in summers and springs than during winters and autumns because wind power had more negative effects on positive mood during spring and summer. This might be because of the fact that people spend more of their leisure time outside in spring and summer more windy than autumn and winter, and our data show this too (Figure 1).

\subsection{Effect of Atmospheric Parameters on RT}

In the springtime time of the experiment, atmospheric pressure and wind velocity negatively affected and increased reaction time of males. In females in springtime, wind velocity negatively affected and increased RT but only at the beginning of test positively affected and decreased variation of RT. In the autumn time of experiment in males, temperature decreased variation of RT but atmospheric pressure increased it, but in females temperature increased RT at the beginning of test. In the wintertime, air temperature negatively affected and increased reaction time of males in Shiraz (Table 3).

\subsection{Effect of APF on WAM}

Pawlaczyk-Luszczyńiska et al. 2005 [47] indicated that AFP (AD) decrease wellbeing. AD actually negatively affected WAM parameters especially in males. In the springtime of experiment, $\mathrm{AD}$ decreased activity and mood in males but in females AD only decreased activity. In the autumn time $\mathrm{AD}$ decreased wellbeing and activity in males but didn't affect females. In the wintertime AD decreased activity and mood in males. These results indicate the negative influence of $\mathrm{AD}$ on activity of males (Table 4).

\subsection{Effect of APF on RT}

Broadbenta 1957 [48] and Pawlaczyk-Luszczyńiska et al. 2005 [47] showed that APF (AD) negatively affected and increased reaction time. In our experiment it is shown that in the most time increase of AD causes increases of RT and has negative effects of AD on RT. In the springtime of experiment, increase of $\mathrm{AD}$ more negatively affected RT of females and increased average and variations of RT. It shows the most negative influence of $\mathrm{AD}$ in females in the spring period. In the autumn time in males AD increased variation of RT at the beginning of the test and in most of the periods, but $\mathrm{AD}$ in some periods in the females reduced variation of RT due to improvement of FS in females. In the wintertime of experiment $\mathrm{AD}$ in males positively affected and decreased some variations of RT at the beginning of test (Table 4).

These results make us judge it as a powerful destructor for the task performed during this period of year on males. In our experiment it is shown more negative effects of AFP on the females in springtime and on the males in autumn time of experiment.

Even though APF has low amplitudes (frequencies below $0.03 \mathrm{~Hz}$ ), in the investigated groups, there were significant influences of APF on FS. In males in autumn experiment APF in all periods selectively increased 
variation of RT at the beginning and through all the time of the test. As far as researches of RT were conducted in different seasons in spring, autumn and winter, it indicates that APF, which are mostly expressed in autumn period as confirms by our data [19], increase the reaction time for males and lead into the decline of FS, but in the spring AFP increases the reaction time of females and lead into the decline of FS. This effect is less than that in autumn.

Our results indicated that atmospheric pressure fluctuations in ranges of $120-1200 \mathrm{~s}$ (AD1-I period) and 20 - $120 \mathrm{~s}$ (AD2-II period) were more effective (especially negative) on psychological self-assessment (wellbeing, activity and mood) and in ranges of $10-20 \mathrm{~s}$ (AD3-III period) and 5 - $10 \mathrm{~s}$ (AD4-IV period), they were more effective on the indexes of RT in comparison to other periods, which were the evidence of such more bioeffective frequencies. Our research shows more negative effects of APF on reaction time and FS of human especially observed in autumn period of the year. It is necessary to notice the presence of a determinant factor in our research which influenced not only directly on the FS but also enhanced the influence of other factors. In our research, such factor was found out to be wind velocity.

\section{REFERENCES}

[1] Mesheriakov, B. and Zinchenko, V. (2004) The big psychological dictionary. Olma-Press.

[2] Pristrom, A.M. and Mrochek, A.G. (2002) Meteosensitiveness. Medicine, 2, 37-39.

[3] Kolosova, O.A. and Mindlina, G.E. (1987) Effect of meteo- and heliofactors on the state of the autonomic ervous system and the adaptive capacity of man. Zhurnal Nevropatologii I Psikhiatrii Imeni S. S. Korsakova, 87, 136143.

[4] Makinen, T.M., Palinkas, L.A., Reeves, D.L., et al. (2005) Effect of repeated exposures to cold on cognitive performance in humans. Physiology \& Behavior, 87, 166-176. http://dx.doi.org/10.1016/j.physbeh.2005.09.015

[5] Davous, P., lamour, Y., debrand, E. and Rondot, P. (1987) A comparative evaluation of the short orientation memory concentration test of cognitive impairment. Journal of Neurology, Neurosurgery \& Psychiatry, 50, 1312-1317. http://dx.doi.org/10.1136/jnnp.50.10.1312

[6] Marchenko, T.K. (1998) The effect of heliogeophysical and meterologic factors on the human body. Fiziologiia Cheloveka, 24, 122-127.

[7] Coleshaw, S.R.K., Van Someren, R.N.M., Wolff, A.H., Davis, H.M. and Keatinge, W.R. (1983) Impaired memory registration and speed of reasoning caused by low temperature. Journal of Applied Physiology, 55, 27-31.

[8] Palinkas, L.A. (2001) Mental and cognitive performances in the cold. International Journal of Circumpolar Health, 60, 430-439.

[9] Assman, D. (1996) Sensitiveness of man to the weather.
Gidrometizdat, Leningrad, 246 p.

[10] Cooke, L.J., Rose, MS. And Becker, W.J. (2000) Chinook winds and migraine headache. Neurology, 54, 302-307. http://dx.doi.org/10.1212/WNL.54.2.302

[11] Trepińska, J., Piotrowicz, K., Bakowski, R., Bolechała, F. and Trela, F. (2005) Influence of weather factors on suicidal hangings. Przeglad Lekarski, 62, 788-794.

[12] Rosen, S. (1979) Weathering. How the atmosphere conditions your body, your mind, your moods, and your health. M. Evans and Company, New York.

[13] Sulman, F.G. (1976) Health, weather and climate. In: van der, L.R., Ed., Perspectives in Medicine, Karger, Basel, 166.

[14] Lee, A.J. and Garraway, W.M. (2000) The influence of environmental factors on rugby football injuries. Journal of Sports Sciences, 18, 91-95. http://dx.doi.org/10.1080/026404100365153

[15] Bedard, J. and Georges, T.M. (2000) Atmospheric infrasound. Physics Today, 53, 32-37. http://dx.doi.org/10.1063/1.883019

[16] Čulić, V., Silić, N. and Mirić, D. (2005) Triggering of ventricular ectopic beats by emotional, physical, and meteorologic stress: Role of age, sex, medications, and chronic risk factors. Croatian Medical Journal, 46, 894-906.

[17] Delyukov, A. and Didyk, L. (1999) The effects of extralow-frequency atmospheric pressure oscillations on human mental activity. International Journal of Biometeorology, 43, 31-37. http://dx.doi.org/10.1007/s004840050113

[18] Broner, N. (1978) The effect of low frequency noise on people. Journal of Sound and Vibration, 58, 483-500. http://dx.doi.org/10.1016/0022-460X(78)90354-1

[19] Didyk, L.A., Deliukov, A.A., Gorgo, Iu.P. and Semenova, I.A. (2000) Effect of extralow frequency variations of atmospheric pressure on voluntary attention parameters. Fiziologiia Cheloveka, 26, 55-60.

[20] Didyk, L.A., Bogdanov, V.B., Lysenko, V.A., Didyk, N.P., Gorgo, Y.P. and Dirckx, J.J. (2007) The effects of slight pressure oscillations in the far infrasound frequency range on the pars flaccida in gerbil and rabbit ears. International Journal of Biometeorology, 51, 221-231.

[21] Didyk, L.A., Dirckx, J.J., Bogdanov, V.B., Lysenko, V.A. and Gorgo, Y.P. (2007) The mechanical reaction of the pars flaccida of the eardrum to rapid air pressure oscillations modeling different levels of atmospheric disturbances. Hearing Research, 223, 20-28. http://dx.doi.org/10.1016/j.heares.2006.09.009

[22] Didyk, L.A., Gorgo, Y.P., Dirckx, J.J., Bogdanov, V.B., Buytaert, J.A., Lysenko, V.A. Didyk, N.P., Vershygora, A.V. and Erygina, V.T. (2008) Atmospheric pressure fluctuations in the far infrasound range and emergency transport events coded as circulatory system diseases. International Journal of Biometeorology, 52, 553-561. http://dx.doi.org/10.1007/s00484-008-0163-6

[23] Gossard, E.E. and Hooke, W.H. (1975) Waves in the Atmosphere: Atmospheric infrasound and gravity wavesTheir generation and propagation. Elsevier, New York.

[24] Green, J.E. and Dunn, F. (1968) Correlation of naturally 
occurring infrasonic and selected human behavior. Journal of the Acoustical Society of America, 44, 1456-1457. http://dx.doi.org/10.1121/1.1911286

[25] Suchkina, E.G. (1985) Effect of meteorological factors on human psychophysiologic reactions. Fiziologiia Chelove$k a$, 11, 470-473.

[26] Richner, H. and Graber, W. (1978) The ability of nonclassical meteorological parameters to penetrate into buildings. International Journal of Biometeorology, 22, 242-248. http://dx.doi.org/10.1007/BF01552805

[27] Rockley, T.J. and Hawke, W.M. (1992) The middle ear as a baroreceptor. Acta Oto-Laryngologica, 112, 816-823. http://dx.doi.org/10.3109/00016489209137479

[28] Stenfors, L.E., Salen, B. and Winblad, B. (1979) The role of the pars flaccida in the mechanics of the middle ear. Acta Oto-Laryngologica, 88, 395-400. http://dx.doi.org/10.3109/00016487909137184

[29] Marchenko, T.K. (1998) The effect of heliogeophysical and meterologic factors on the human body. Fiziologiia Cheloveka, 24, 122-127.

[30] Naito, Y., Ito, J., Tsuji, J. and Honjo, I. (1988) The influence of middle ear pressure on the otolith system in cats. Archives of Oto-Rhino-Laryngology, 245, 321-324. http://dx.doi.org/10.1007/BF00464641

[31] Suzuki, M., Kitano, H., Yazawa, Y. and Kitajima, K. (1995) The influence of rates of pressure change on pressure-induced vestibular response in guinea pigs. Journal of Otolaryngology of Japan, 98, 820-824. http://dx.doi.org/10.3950/jibiinkoka.98.820

[32] Fraster, D.C. and Jackson, K.F. (1955) Effect of heat stress on serial reaction time in man. Nature, 176, 976977. http://dx.doi.org/10.1038/176976b0

[33] Jordan, N., Sagar, H.J. and Cooper, J.A. (1992) Cognitive components of reaction time in Parkinson's disease. Journal of Neurology, Neurosurgery \& Psychiatry, 55, 658664. http://dx.doi.org/10.1136/jnnp.55.8.658

[34] Loskutova, T.D. (1975) Evaluation of the fructional state of the human central nervous system according to parameters of simple motor reactions. Fiziologicheskiu Zhurnal SSSR Imeni I. M. Sechenova, 61, 3-12.

[35] Plainis, S. and Murray, I.J. (2002) Reaction times as an index of visual conspicuity when driving at night. Ophthalmic and Physiological Optics, 22, 409-415. http://dx.doi.org/10.1046/j.1475-1313.2002.00076.x

[36] Van der Berg, J. and Neely, G. (2006) Performance on a simple reaction time task while sleep deprived. Perceptual \& Motor Skills, 102, 589-599. http://dx.doi.org/10.2466/pms.102.2.589-599
[37] Razmjou, S. and Kjellberg, A. (1992) Sustained attention and serial responding in heat: Mental effort in the control of performance. Aviation, Space, and Environmental Medicine, 63, 594-601.

[38] Ellis, H.D., Wilcock, S.E. and Zaman, S.A. (1985) Cold and performance: The effects of information load, analgesics, and the rate of cooling. Aviation, Space, and Environmental Medicine, 56, 233-237.

[39] Rammsayer, T.H., Bahner, E. and Netter, P. (1995) Effects of cold on human information processing: Application of a reaction time paradigm. Integrative Physiological and Behavioral Science, 30, 34-45.

[40] Chand, P.K. and Murthy, P. (2008) Climate change and mental health. Regional Health Forum, 12, 43-48.

[41] Postolache, T.T., Mortensen, P.B., Tonelli, L.H., Jiao, X., Frangakis. C., Soriano, J.J. and Qin, P. (2010) Seasonal spring peaks of suicide in victims with and without prior history of hospitalization for mood disorders. Journal of Affective Disorders, 121, 88-93.

http://dx.doi.org/10.1016/j.jad.2009.05.015

[42] Rocchi, M.B., Sisti, D., Miotto, P. and Preti, A. (2007) Seasonality of suicide: Relationship with the reason for suicide. Neuropsychobiology, 56, 86-92. http://dx.doi.org/10.1159/000111538

[43] Woo, J.M., Okusaga, O. and Postolache, T.T. (2012) Seasonality of suicidal behavior. International Journal of Environmental Research and Public Health, 9, 531-547. http://dx.doi.org/10.3390/ijerph9020531

[44] Doskin, V.A., Lavrent'eva, N.A., Strongina, O.M. and Sharaĭ, V.B. (1975) "SAN" psychological test applicable to studies in the field of work physiology. Gigiena Truda I Professionalnye Zabolevaniia, 5, 28-32.

[45] Brereton, F., Clinch, J.P. and Ferreira, S. (2008) Happiness, geography and the environment. Ecological Economics, 65, 386-396. http://dx.doi.org/10.1016/j.ecolecon.2007.07.008

[46] Denissen, J.J., Butalid, L., Penke, L. and Van Aken, M.A. (2008) The effects of weather on daily mood: A multilevel approach. Emotion, 8, 662-667. http://dx.doi.org/10.1037/a0013497

[47] Pawlaczyk-Luszczyńiska, M., Dudarewicz, A., Waszkowska, M., Szymczak, W. and Sliwińska-Kowalska, M. (2005) The impact of low-frequency noise on human mental performance. International Journal of Occupational Medicine and Environmental Health, 18, 185-198.

[48] Broadbenta, D.E. (1957) Effects of noises of high and low frequency on behavior. Ergonomics, 1, 21-29. http://dx.doi.org/10.1080/00140135708964568 